\title{
Pre-processing of hematite-doped alumina granules for Selective Laser Melting.
}

\author{
M. Makowska ${ }^{a}$, S. Pfeiffer ${ }^{b}$, N. Casati ${ }^{c}$, K. Florio $^{d}$, Marc Vetterli $^{e}$, K. Wegener $^{d}$, T. Graule $^{b}$, H. van \\ Swygenhoven $^{\text {a }}$ \\ ${ }^{a}$ Photons for Engineering and Manufacturing Group, Paul Scherrer Institute, Villigen-PSI, 5232 \\ ${ }^{b}$ Laboratory for High Performance Ceramics, Empa - Swiss Federal Laboratories for Materials Science and \\ Technology, Überlandstrasse 129, 8600 Dübendorf, Switzerland \\ ${ }^{c}$ Swiss Light Source, Paul Scherrer Institut, 5232 Villigen Psi, Switzerland \\ ${ }^{d}$ Institute of Machine Tools and Manufacturing, ETH Zurich, Leonhardstrasse 21, 8092 Zurich, Switzerland \\ ${ }^{e}$ Inspire $A G$, icams
}

Keywords

D. $\mathrm{Al}_{2} \mathrm{O}_{3}$, A. calcination, A. Powders: solid state reaction, B. X-ray methods, Selective Laser Melting

\begin{abstract}
Structure and composition evolution of $\alpha-\mathrm{Fe}_{2} \mathrm{O}_{3}$ doped alumina granules during calcination is investigated by means of synchrotron X-ray powder diffraction. The $\alpha-\mathrm{Fe}_{2} \mathrm{O}_{3}$ nanoparticles are added to increase the absorption of laser light, however, they also play a significant role in transition kinetics of alumina. It is shown that calcination in air leads to implementation of $\mathrm{Fe}^{3+}$ ions in corundum structure, while calcination in reducing atmosphere leads to creation of metallic iron. Moreover, it is demonstrated that for alumina granules consisting of a mixture of micron-size $\alpha$ alumina, submicron $\alpha$-alumina and nano-size $\gamma-/ \delta$--alumina, it is possible to obtain a system composed of two corundum-type structures with different Fe doping levels and the ratio of these two phases can be controlled by calcination temperature.
\end{abstract}

\section{Introduction}

Alumina is well known for its excellent thermal and mechanical properties. Moreover, it is a very good electrical insulator and it has high corrosion resistance in a very broad range of temperatures and a good biocompatibility. For these reasons, it is one of the most commonly used ceramic materials. Its typical applications are among others, isolation parts in electrical components, mechanical parts, parts used in high temperature technologies and in medical implants and devices.

This document is the accepted manuscript version of the following article: Makowska, M., Pfeiffer, S., Casati, N., Florio, K., Vetterli, M., wegener, K., ... van Swygenhoven, H. (2019). Pre-processing of hematite-doped alumina granules for selective laser melting. Ceramics International. https://doi.org/10.1016/j.ceramint.2019.05.251

This manuscript version is made available under the CC-BY-NC-ND 4.0

1icense http://creativecommons.org/1icenses/by-nc-nd/4.0/ 
The already broad application field of alumina is, however, somehow restricted due to geometrical limitations inherent to conventional production techniques. To make ceramics a viable material for a large number of applications available in large-scale production, all manufacturing technologies that are known for metals need to be extended to ceramics, also the additive manufacturing (AM) technology, which in metals provides significant advantages for geometrically complex and technical parts. AM techniques such as Selective Laser Melting (SLM) or Sintering (SLS) - techniques already commonly applied to polymer and metal parts manufacturing [1], [2] - hold a great potential for direct manufacturing of complex-shaped ceramic elements [3]. This potential is reflected in the growing number of communications in literature on this topic. However, SLM manufactured ceramic components struggle with poor mechanical properties. The microstructure contains usually a large number of cracks and porosity, the density is relatively low and the surface shows important roughness [4]-[6]. Also, visual properties, e.g. color and surface roughness, which are important for dental applications are difficult to control [7]. However, transferring the SLM manufacturing technology from metal to ceramic materials like alumina, silica or zirconia is not a straightforward task due to high melting point of ceramics, low thermal shock resistance and different mechanisms of interaction with laser light [8]-[11].

In order to optimize the SLM process for ceramics, it is crucial to understand the interaction of the laser light with the starting ceramic powder and to optimize not only the laser source but also the laser scan parameters and the laser light absorption of the powder. To enhance the light absorption in the infrared region, dopants can be used such as carbon and SiC additives [4], [12] or by using a small amount of different metal oxides, e.g. $\mathrm{Fe}_{2} \mathrm{O}_{3}$ as a dopant in alumina granules. As already demonstrated by the authors, the presence of $1 \mathrm{wt} \%$ of the dopant has significant effect on the optical properties of the powder, but also on the final properties of the manufactured parts [13], [14].

Both corundum $\left(\alpha-\mathrm{Al}_{2} \mathrm{O}_{3}\right)$ and hematite $\left(\alpha-\mathrm{Fe}_{2} \mathrm{O}_{3}\right)$ belong to the same space group $\mathrm{R} \overline{\mathrm{c}} \mathrm{c}$ with the lattice parameters $a=4.760 \AA, c=12.993 \AA$ [15] and $a=5.039 \AA, c=13.740 \AA$ [16], [17], respectively and can form solid solutions in form of $\left(\mathrm{Fe}_{x} \mathrm{Al}_{1-\mathrm{x}}\right)_{2} \mathrm{O}_{3}$. Measured values of solubility 
limits of $\alpha-\mathrm{Fe}_{2} \mathrm{O}_{3}$ in $\alpha-\mathrm{Al}_{2} \mathrm{O}_{3}$ for calcination temperatures $1200^{\circ} \mathrm{C}-1250^{\circ} \mathrm{C}$ were stated by [18], [19] to be in the range of $9-11 \mathrm{~mol} \%$, which corresponds well to phase diagrams from [20], [21]. The presence and concentration of substitution atoms in solid solution of $\alpha-\mathrm{Al}_{2} \mathrm{O}_{3}$ has a strong influence on its optical properties [22], [23] and thus, depending on the laser parameters, even small differences in Fe amount in corundum can tremendously affect the interaction with the laser [13], [14].

Properties and applications of alumina containing different metal oxide additives have been studied since decades [16], [19], [24]-[26] and are still a topic of most recent research [27]-[31] due to the valuable properties of this ceramic material. Effect of adding small amounts of hematite on alumina properties was extensively studied by G.L. Messing, J.Tartaj and J. L. McArdle [24]-[26], [32], who have demonstrated that presence of hematite in alumina can significantly affect its microstructure and grain growth at elevated temperatures. The same group has also shown the seeding effect that $\alpha-\mathrm{Fe}_{2} \mathrm{O}_{3}$ nanoparticles can have on the $\gamma$-to $\alpha$-alumina transition. It was shown that the activation energy for the transformation decreases significantly accelerating its kinetics and that higher densities can be obtained during calcination of $\alpha-\mathrm{Fe}_{2} \mathrm{O}_{3}$ doped alumina.

In this work, granules specially designed for SLM technology and synthesized by spray drying are analyzed by means of synchrotron X-ray powder diffraction. The starting powder for the granule synthesis was a trimodal mixture of micron-size $\alpha$-alumina, submicron $\alpha$-alumina and nano-size $\gamma /$ $\delta$-alumina, where hematite was added as dopant for increasing laser light absorption properties. The effect of hematite doping on the laser light absorption in such granules was demonstrated in our previous work [14]. Moreover, initial results of SLM manufacturing of alumina from noncalcined hematite-doped alumina granules presented in [14] have shown that SLM technique could be successfully applied for printing alumina for hematite doping above $0.7 \mathrm{wt} . \%$, while for lower doping levels absorption of laser light was too low to melt it using similar laser parameters. Fig. 1 illustrates a sketch of such a granule. The aim of this 3-lengthscale design of a granule is to make from the melting process during SLM a gradual process, where the smaller alumina will melt first 
and serve as a gluing matrix. It is expected that partial melting would reduce the formation of thermal stresses leading to microcracking. Spray dried granules are typically heat treated prior to SLM processing in order to improve the density of final parts and to remove organics. In this work, we report on the Fe atoms implementation process in corundum alumina lattice during annealing in air at different temperatures and on the creation of metallic iron phase when using reducing atmosphere.

\section{Material and methods}

\section{Sample preparation}

Powder diffraction measurements are performed on three sets of samples further referred to as "SA", "SB" and "SC" (table 1). Samples SA and SB were prepared to investigate the influence of calcination conditions (temperature and atmosphere) on the structural properties and the distribution of the iron dopant in the granules. The set SA includes ten samples consisting of granules containing a trimodal mixture of alumina and $\alpha-\mathrm{Fe}_{2} \mathrm{O}_{3}$, calcined in air at different temperatures between Room temperature (RT) and $-1600^{\circ} \mathrm{C}$. The samples from the SB set are prepared from the same production batch as $\mathrm{SA}$, however, calcined in a mixture of $98 \% \mathrm{Ar}$ and $2 \%$ $\mathrm{H}_{2}$ in a range of $\mathrm{RT}-1400^{\circ} \mathrm{C}$. The trimodal alumina granules were obtained by means of spray drying of a dispersed mixture of several components: 63.5 wt\% micron-size $\alpha$-alumina (AA3 from Sumitomo, $D_{50}=3.0 \mu \mathrm{m}$ ), 24 wt\% submicron $\alpha$-alumina (AA03 from Sumitomo, $D_{50}=303 \mathrm{~nm}$ ), $9 \mathrm{wt} \%$ nano-size $\gamma / \delta$ alumina (Aeroxide AluC from Evonik, company given value of the grain size $D_{50}=13$ $\mathrm{nm})$ and $1 \mathrm{wt} \%$ of $\alpha-\mathrm{Fe}_{2} \mathrm{O}_{3}$ (L2818D from BASF, $\mathrm{D}_{50}=11 \mathrm{~nm}$ ) dispersed in deionized water by means of 0.5 wt\% dispersing agent (ammonium citrate dibasic) and with 2 wt\% binder (PEG35000) added to achieve non broken-granules. XRD measurements of the pure dopant performed prior to adding to the alumina granules (not presented in this article) have shown that the only crystalline phase present in the powder was the $\alpha-\mathrm{Fe}_{2} \mathrm{O}_{3}$ phase. The amount of different alumina powders was optimized for achieving good granulation and especially for highest packing density, which is a crucial factor for powder for SLM technology. The detailed description of optimization granule 
composition can be found in our previous work [13]. The amount of hematite dopant was defined by systematic studies of SLM processing of non-calcined granules (this amount provided sufficient absorption for SLM) [14]. By spray drying, granules with median diameter $\left(D_{50}\right)$ of $40 \mu \mathrm{m}$ were obtained, as schematically illustrated in fig.1. Detailed description of the synthesis and characterization of the studied alumina granules can be found elsewhere [13]. Fig. 2 presents optical microscopy images of the capillaries filled with granules and calcined at different temperatures in oxidizing (fig. 2 a) and in reducing (fig. 2 b) atmosphere, revealing different colouring of the samples.

To investigate whether a trimodality of the alumina granules is critical for the structure changes upon the heat treatment, two additional samples (set $\mathrm{SC}$ ) were prepared from single alumina components. The monomodal alumina granules SC1 and SC2 were spray-dried from two powder compositions: 1. nano $\gamma-/ \delta$ - alumina (AluC) with 1.79 wt\% $\alpha-\mathrm{Fe}_{2} \mathrm{O}_{3}, 2$. $\alpha$-alumina AA03 with 0.95 wt $\% \alpha-\mathrm{Fe}_{2} \mathrm{O}_{3}$, both calcined at $1400{ }^{\circ} \mathrm{C}$ in air.

Table 1 presents the summary of the samples investigated in this work. Calcination process for each sample, except for sample SB1, was performed in three steps: heating with rate $2^{\circ} \mathrm{C} / \mathrm{min}, 2 \mathrm{~h}$ holding time at the target temperature and a cooling rate $5^{\circ} \mathrm{C} / \mathrm{min}$. For sample SB1 the holding time was $0.5 \mathrm{~h}$ (heating and cooling rates were the same).

\begin{tabular}{|c|c|c|c|c|c|}
\hline \multirow{3}{*}{$\begin{array}{l}\text { Sample name } \\
\text { SA1-SA10 }\end{array}$} & \multicolumn{4}{|c|}{ composition } & \multirow{3}{*}{$\begin{array}{l}\begin{array}{l}\text { Calcination } \\
\text { conditions }\end{array} \\
\text { Air, RT- } 1600^{\circ} \mathrm{C}\end{array}$} \\
\hline & AA3 [\%] & AA03 [\%] & Aluc [\%] & $\alpha-\mathrm{Fe}_{2} \mathrm{O}_{3}[\%]$ & \\
\hline & 64.8 & 24.6 & 9.6 & 1.0 & \\
\hline SB1-SB5 & 64.8 & 24.6 & 9.6 & 1.0 & $\begin{array}{l}98 \% \mathrm{Ar}: 2 \% \mathrm{H}_{2}, \\
800{ }^{\circ} \mathrm{C}-1400^{\circ} \mathrm{C}\end{array}$ \\
\hline $\mathrm{SC} 1$ & 0 & 0 & 98.21 & 1.79 & Air, $1400^{\circ} \mathrm{C}$ \\
\hline $\mathrm{SC} 2$ & 0 & 99 & 0 & 0.95 & Air, $1400^{\circ} \mathrm{C}$ \\
\hline
\end{tabular}


Table 1 Summary of the investigated samples, where: AA3: micron-size $\alpha-\mathrm{Al}_{2} \mathrm{O}_{3}\left(\mathrm{D}_{50}=3.0 \mu \mathrm{m}\right)$, AA03: submicron $\alpha-\mathrm{Al}_{2} \mathrm{O}_{3}\left(D_{50}=303 \mathrm{~nm}\right)$, AluC: nano-size $\gamma / \delta-\mathrm{Al}_{2} \mathrm{O}_{3}\left(D_{50}=13 \mathrm{~nm}\right)$. The given concentration values of different components correspond to the powders after heating (when all the organic materials were removed).

\section{Powder diffraction studies}

High resolution powder diffraction (PD) measurements were performed at the Material Science (MS) beamline [33] at the Swiss Light Source (SLS) utilizing the Mythen microstrip detector [34]. The nominal X-ray beam energy was $22 \mathrm{keV}$ for the SA and SB sets and $17.5 \mathrm{keV}$ for the SC set. For precise wavelength calibration, silicon and lanthanum hexaboride standards from NIST (SRM 640d and 660, respectively) were used and the obtained wavelength values were $0.56390 \AA$ and 0.71019 $\AA$, respectively. For the PD experiments, all the powders were placed in glass capillaries with a diameter of $300 \mu \mathrm{m}$ and measured in the transmission mode (Debye-Scherrer geometry).

Quantification of the phases present in the measured samples was obtained from Rietveld refinement of the structural models fitted to the measured diffraction patterns using TOPAS Bruker AXS software [35].

\section{BET measurements}

The diffusion of Fe atoms into crystal lattice is strongly dependent on the surface area of the particles. Specific surface area (SSA) and average particle size of each component powder of the trimodal alumina granules was measured by BET (Brunauer-Emmett-Teller) method (SA 3100, Beckman Coulter, Germany). This analysis technique is based on the physical adsorption of nitrogen molecules on the particle surface. Before the measurements, the raw powders were dried for two hours at $180{ }^{\circ} \mathrm{C}$ under synthetic air to remove adsorbed water from the particle surfaces. A BET average particle size was calculated from the density (measured by helium pycnometer) and the respective specific surface area assuming monomodal spherical particles.

\section{Results}

PD studies of the alumina granules calcined at different temperatures reveal significant differences in the crystallographic structure appearing after calcination temperatures above $700^{\circ} \mathrm{C}$. Fig. 3 
presents the results of these measurements for powders calcined in air at $700^{\circ} \mathrm{C}, 800^{\circ} \mathrm{C}, 900^{\circ} \mathrm{C}$ and $1000^{\circ} \mathrm{C}$ (SA2-SA5). It is apparent that hematite and $\gamma$-alumina phases gradually disappear in this temperature range. The $\gamma$-alumina phase amount decreases which can be ascribed to the transition of $\gamma$ to $\alpha$ phase of alumina at elevated temperatures [36]-[38].

Above $1000^{\circ} \mathrm{C}$ both hematite and $\gamma$-alumina phases vanish completely (within the detection limit of the method, which is about $0.01 \%$ ), which is also reflected in the change of color of the powder from orange to light yellow (almost white). Fig. 4 presents as an example the diffraction pattern measured for the sample calcined in air at $1200^{\circ} \mathrm{C}$, including fitted model refined with following parameters: $\mathrm{Rwp}=2.98 \%, \mathrm{Rp}=3.17 \%$. The positions of all the visible reflections are related to the corundum structure. Zooming in at the peak profile reveals that for every single corundum reflection in the PD patterns, which are invariant to the calcination temperature, there is a second peak present shifted to the lower $2 \theta$ angle, suggesting the presence of a second very similar structure. The inset in the fig. 4 presents the corundum reflection measured for samples SA5-SA8 (calcined at $1000-1300^{\circ} \mathrm{C}$ ). In each of these samples two phases with slightly different unit cell size are apparent. The same effect was observed for sample SA9 (calcined at $1400^{\circ} \mathrm{C}$ ), but interestingly, for sample SA10 (calcined at $1600^{\circ} \mathrm{C}$ ) only single, but broader peaks were observed (fig. 5). It is important to note that the powder diffraction patterns of samples SA5-SA10 did not contain any other phase besides these two phases with similar metrics. Moreover, the additional phase appears at the same calcination temperature, where the hematite phase disappears, suggesting that its nature is likely that of a solution of $\alpha-\mathrm{Fe}_{2} \mathrm{O}_{3}$ in $\alpha-\mathrm{Al}_{2} \mathrm{O}_{3}$.

Fig. 5 shows the fittings of the reflection of samples SA1 and SA5-SA10 assuming two corundum structures with different lattice parameters caused by different concentrations of $\mathrm{Fe}$ atoms occupying $\mathrm{Al}$ sites in $\alpha-\mathrm{Al}_{2} \mathrm{O}_{3}$ lattice. The green reflection represents the peak corresponding to a Fe-doped alumina and is obtained by fitting refinement for different doping levels. Blue lines represent the fitted peaks of the $\alpha$-alumina structure with minor or negligible Fe doping (expect for the SA10, where only one phase is fitted). Fig. 6 a, b and c show the evolution of the lattice 
constants " $a$ " and " $c$ " and the unit cell volume " $V$ " evaluated for the two phases ("pure corundum", "Fe-doped corundum") as function of sintering temperature, obtained by Rietveld refinement. The blue line corresponds with the phase with minor or no Fe content, and the green line corresponds with the phase containing Fe. As the phase represented by the blue line (in fig. 5) only very slightly changes with calcination temperature and remains almost identical to the lattice parameters obtained for sample SA1 (non-calcined), it can be assumed for further analysis that the doping level of Fe in this phase was negligible and thus this phase is further referred to as "pure corundum" or "pure $\alpha$-alumina". In contrast to the "pure corundum" phase, lattice parameters of the "Fe-doped alumina" phase change significantly with increasing temperature, which is reflected in the diffraction peaks shift to higher $2 \theta$ values. Furthermore, the integrated peak intensity increases indicating an increase of the total amount of this phase and the width of the diffraction peaks is narrowing suggesting growth of the crystallites.

The powder diffraction patterns measured for the samples SB, which were prepared from the same ingredient powder as for SA, but calcined in reducing atmosphere of $98 \% \mathrm{Ar}: 2 \% \mathrm{H}_{2}$, are presented in fig. 7. Rietveld refinement for the data presented in fig. 7 a) was performed with following parameters: $\mathrm{Rwp}=3.06 \%, \mathrm{Rp}=3.86 \%$. Comparison of samples $\mathrm{SB2}-\mathrm{SB} 5$ calcined for $2 \mathrm{~h}$ (at $800^{\circ} \mathrm{C}$, $1000^{\circ} \mathrm{C}, 1200^{\circ} \mathrm{C}$ and $1400^{\circ} \mathrm{C}$, respectively) and sample SB1 calcined for $0.5 \mathrm{~h}$ at $800^{\circ} \mathrm{C}$ revealed no Fedoping of the corundum lattice, but instead the presence of another phase that was not observed in the SA samples calcined in air. All the powders calcined in reducing atmosphere turned dark gray (fig.2), which most likely is related to appearance of this new phase, which was identified as bcc iron. Another important observation is that $\gamma$ - to $\alpha$-alumina phase transformation is fully accomplished only for powder calcined at $1200^{\circ} \mathrm{C}$ (SB3), while the sample calcined at $1000^{\circ} \mathrm{C}$ (SB2) still contains a significant amount of $\gamma-/ \delta$-alumina phase.

Measurements of the samples from the set SC (calcined at $1400{ }^{\circ} \mathrm{C}$ in air) are presented in fig. 8. SC1 and SC2 prepared from only $\gamma-/ \delta$ - or $\alpha$ - alumina component, respectively and doped with $\mathrm{Fe}_{2} \mathrm{O}_{3}$ do not show the "double" corundum structure and contain only one phase of solid solution of $\alpha$ - 
$\mathrm{Fe}_{2} \mathrm{O}_{3}$ in $\alpha-\mathrm{Al}_{2} \mathrm{O}_{3}$. The peak shift with respect to the pure corundum observed for SC1 and SC2 was significantly different for both samples, which is due to a different hematite doping level: $1.79 \%$ and $0.95 \%$ for SC1 and SC2, respectively.

\section{Discussion}

In the samples SA1-SA10, calcined in air, the $\gamma$ - $\alpha$-alumina phase transition takes place below $1000^{\circ} \mathrm{C}$ and Fe atoms starts to replace the Al atoms in the corundum lattice above this temperature. The evaluated amount of Fe-doped corundum phase observed in granules calcined at $1000^{\circ} \mathrm{C}$ (SA5) was $(9.9 \pm 1.0)$ wt\%, which corresponds well to the amount of nano-alumina (Aeroxide AluC) in the initial composition. This value along with the strong peak broadening, related to small crystallite sizes, indicate that at this temperature iron atoms were implemented mainly in the granule fraction originating from nano-alumina component. According to the studies presented in [26], [38], [39], the $\gamma$ - to $\alpha$-alumina phase transformation at $1000^{\circ} \mathrm{C}$ is a very slow process and the heat treatment time applied in this work would be too short to fully transform pure $\gamma$ - alumina already at $1000^{\circ} \mathrm{C}$. However, J. L. McArdle and G.L. Messing [26] have demonstrated that the presence of $\alpha-\mathrm{Fe}_{2} \mathrm{O}_{3}$ nanoparticles significantly lowers the activation energy for the overall $\gamma$ - to $\alpha$-alumina phase transformation, which explains the accelerated transformation observed in the samples analyzed here. Since $\alpha-\mathrm{Fe}_{2} \mathrm{O}_{3}$ nanoparticles, which were distributed homogenously in the trimodal granules, act as seeds for creation of Fe-doped $\alpha-\mathrm{Al}_{2} \mathrm{O}_{3}$ crystals and by taking into account large specific surface area of the nano $\gamma-\mathrm{Al}_{2} \mathrm{O}_{3}$ particles, it is not surprising that at first solid solution $\left(\mathrm{Fe}_{\mathrm{x}} \mathrm{Al}_{1-} \mathrm{x}\right)_{2} \mathrm{O}_{3}$ in the trimodal granules was observed only in the nano-particles fraction. A graphical interpretation of the derived model describing the granule after calcination at $1000^{\circ} \mathrm{C}$ is given in fig. 9 .

Rising the calcination temperature results in increasing the amount of Fe-doped corundum phase. At the same time, the peak positions in the pattern shift to higher $2 \theta$ values, which is an evidence of decreasing of the unit cell size. These observations indicate that at higher temperatures Fe atoms diffuse from the fraction originating from nano-alumina to the fraction originating from sub-micron alumina, and thus the amount of Fe-doped alumina increases. Since now the same amount of Fe 
atoms is distributed in a bigger amount of material, Fe occupancy in the corundum crystal unit cell must decrease and consequently the lattice parameters decrease as well. Moreover, peaks corresponding to the Fe-doped phase increase in intensity and narrow. This observation is related to crystallite growth of the initially nano-sized particles.

Assuming that all the Fe atoms from hematite added to the granules (1 wt. \%) are distributed only in the phase referred to as Fe-doped corundum and given the fraction of this phase in the samples SA5, SA6, SA7 and SA8, concentration of Fe atoms (in the Fe-doped corundum phase) was estimated to be $4.9 \%, 4.1 \%, 2.8 \%$ and $2.3 \%$ respectively ( $\mathrm{mol} \%$ ). The values of evaluated lattice parameters " $a$ " and " $c$ " with corresponding estimated doping levels are in very good agreement with the data presented by Brown et al. [19], who reported on the dependence of the corundum lattice parameters on the molar fraction of $\alpha-\mathrm{Fe}_{2} \mathrm{O}_{3}$ in solid solution with corundum. This confirms that in those samples, approximately all the available iron atoms were implemented in the lattice of the Fe-doped alumina phase.

Rietveld refinement of the diffraction pattern of SA9 sample showed that at $1400^{\circ} \mathrm{C}$ the amount of Fe-doped corundum phase reached $(35.3 \pm 1.5)$ wt $\%$, which within measurement uncertainty is equal to the summed amount of nano-alumina $(9.6 \%)$ and sub-micron alumina $(24.6 \%)$ of the initial mixture. In this case, the lattice parameters change of the phase illustrated by the blue lines in fig. 5 was very small, but already measurable, meaning that minor amount of the Fe atoms diffused also to the structure originating from the largest alumina particles fraction. Hindered diffusion of Fe atoms to this fraction at lower calcination temperatures is explained by the differences in surface area of the three alumina granule components as measured by BET method: AA3: $0.4 \mathrm{~m}^{2} / \mathrm{g}$, AA03: $5.5 \mathrm{~m}^{2} / \mathrm{g}$, AluC: $95.3 \mathrm{~m}^{2} / \mathrm{g}$. Due to significantly smaller surface area, it is expected that the AA3 particles have very low ability to implement Fe atoms as compared with AA03 and with Aeroxide Aluc.

The diffraction peaks corresponding to the two phases obtained at $1400{ }^{\circ} \mathrm{C}$ are very close, but clearly distinguishable, while for the samples calcined at $1600^{\circ} \mathrm{C}$ only single, but broader peaks 
were measured. This indicates that, at $1600^{\circ} \mathrm{C}, \mathrm{Fe}^{3+}$ ions diffused also to the fraction originating from the largest alumina particles. The sudden rise of the lattice parameters represented by the blue lines in fig. 6 after $1400^{\circ} \mathrm{C}$ reveals that diffusion of $\mathrm{Fe}^{3+}$ ions takes place mainly in the temperature range between $1400^{\circ} \mathrm{C}$ and $1600^{\circ} \mathrm{C}$, which is also a standard sintering temperature range of alumina in technical ceramics. For a homogeneous solid solution, a narrowing of the diffraction peaks is to be expected with increasing temperature. This was not observed, which is likely caused by non- homogeneous iron distribution in the corundum lattice. Fig. 9 presents schematically the changes in the distribution of the $\mathrm{Fe}^{3+}$ ions for the different fractions of alumina in a granule.

Measurements of samples SC1, SC2 calcined under the same conditions as sample SA9 $\left(1400{ }^{\circ} \mathrm{C}\right.$ in air, fig. 8), revealed the creation of only one Fe-doped corundum phase, which additionally confirms that two different corundum-like phases can be obtained only if the initial powder is composed of mixture of alumina particles with different ability to implement dopant atoms.

In contrast to the whitening effect during calcination of the orange hematite doped alumina granules in air, a reducing atmosphere results in blackening of the powders. In the powder diffraction patterns of samples SC1-SC5 (fig. 7), no shift of the corundum peaks and consequently no change in lattice constants was observed. Thus, it can be concluded that no doping of corundum lattice with $\mathrm{Fe}^{3+}$ occurred in this case. This is probably because already at $800{ }^{\circ} \mathrm{C}, \mathrm{Fe}^{3+}$ was reduced to the zero-oxidation state and started to form bcc Fe phase. The presence of bcc Fe is apparent in all the SB samples and can explain the dark grey color of the powders. Formation of Fe bcc phase already at $800^{\circ} \mathrm{C}$ is also reflected in a slower $\gamma$ - to $\alpha$-alumina phase transformation as compared with granules calcined in air, since no seeding with $\alpha-\mathrm{Fe}_{2} \mathrm{O}_{3}$ nanoparticles can take place. The narrow shoulder at the iron diffraction peaks observed for sample SB4 (calcined at $1200{ }^{\circ} \mathrm{C}$ ) and a very broad shoulder observed for sample SB5 (calcined at $1400{ }^{\circ} \mathrm{C}$ ) may be related to the vanishing of $\gamma$ - alumina phase, as it occurs at the same temperature. These observed shoulders indicate a presence of other phases from the same space group as Fe bcc $(I \mathrm{~m}-3 \mathrm{~m})$. Based on Rietveld 
refinement of model fitted to the diffraction data, these additional peaks could be identified as the AlFe bcc structure, meaning that some Al atoms most likely originating from $\gamma$-alumina phase were also reduced to zero oxidation state.

In summary, granules calcined in reducing atmosphere were composed of pure alumina particles and metallic Fe or AlFe particles (within the detection limit of the applied method, which is about $0.01 \%)$. A graphical interpretation of the phenomena observed in granules calcined in reducing atmosphere is presented in fig. 10.

\section{Conclusions}

Based on the analysis of results of powder diffraction measurements, models have been developed describing calcination induced changes in location and distribution of Fe atoms in trimodal alumina granules. It is shown that applying different calcination temperatures and atmospheres to multimodal alumina granules, results in completely different systems from structural and chemical point of view. The initial trimodal alumina granules were synthesized by spray drying from a mixture of micron-size $\alpha$-alumina, submicron $\alpha$-alumina, nano-sized $\gamma$-alumina and nano-sized hematite added for increasing laser light absorption. Annealing of such granules in air leads first to the $\gamma-\alpha$ phase transition that occurs at lower temperature than expected due to seeding function of $\alpha-\mathrm{Fe}_{2} \mathrm{O}_{3}$ nanoparticles. At $1000^{\circ} \mathrm{C}$, a solid solution $\left(\mathrm{Fe}_{x} \mathrm{Al}_{1} \mathrm{x}\right)_{2} \mathrm{O}_{3}$ was observed, originating from hematite and from alumina nano-particles, resulting in a pure corundum and Fe-doped corundum phase. Further increase of the temperature increases the fraction of Fe-doped corundum phase indicating that $\mathrm{Fe}^{3+}$ ions diffuse also into the fraction originating from sub-micron sized alumina particles. At $1600{ }^{\circ} \mathrm{C}$ only one single corundum phase was found, evidencing a homogeneous distribution of $\mathrm{Fe}^{3+}$ ions in all granule fractions as schematically presented in fig. 9.

When similar trimodal alumina granules are calcined in a reducing atmosphere, bcc Fe phase appears at $800{ }^{\circ} \mathrm{C}$, preventing the seeding effect of $\alpha-\mathrm{Fe}_{2} \mathrm{O}_{3}$ nanoparticles and delaying the $\gamma$ $\alpha$ phase transition. At higher calcination temperatures, also AlFe phase was observed. 
The results presented in this work show that by selecting proper calcination conditions (atmosphere and temperature), it is possible to control the crystalline phase, in which Fe exist in the granules. Moreover, in case of calcination in air, it is possible to control the amount of the Fedoped alumina phase in the alumina granules as well as the concentration of Fe atoms implemented in this phase. These two parameters have significant effect on the optical properties, but also on the melting point of the material. Therefore, ability to control these parameters can be helpful in controlling the interaction of laser light with ceramic granules. The direct relation between calcination conditions and the SLM processability as well as the role of dopants in alumina in controlling other properties, for instance mechanical strength, heat conductivity, and thermal expansion coefficient is the scope of the ongoing research.

\section{Acknowledgements}

The authors would like to thank the ETH Board for funding our work within the frame of the SFA

(Strategic Focus Areas) Advanced Manufacturing. Thanks also to Dr. Mario Borlaf (EMPA,

Dübendorf) for helping with the sample preparation.

[1] D. D. Gu, W. Meiners, K. Wissenbach, and R. Poprawe, "Laser additive manufacturing of metallic components: materials, processes and mechanisms," Int. Mater. Rev., vol. 57, no. 3, pp. 133164, 2012.

[2] J.-P. Kruth, G. Levy, F. Klocke, and T. H. C. Childs, "Consolidation phenomena in laser and powder-bed based layered manufacturing," CIRP Ann., vol. 56, no. 2, pp. 730-759, Jan. 2007.

[3] S. L. Sing et al., "Direct selective laser sintering and melting of ceramics: A review," Rapid Prototyping Journal, vol. 23, no. 3. pp. 611-623, 2017.

[4] E. Juste, F. Petit, V. Lardot, and F. Cambier, "Shaping of ceramic parts by selective laser melting of powder bed," J. Mater. Res., vol. 29, no. 17, pp. 2086-2094, Sep. 2014.

[5] J. Deckers, S. Meyers, J. P. Kruth, and J. Vleugels, "Direct selective laser sintering/melting of high density alumina powder layers at elevated temperatures," Phys. Procedia, vol. 56, no. C, pp. 117-124, 2014.

[6] Y. Hagedorn, "Additive Manufacturing of High Performance Oxide Ceramics via Selective Laser Melting," Fraunhofer Institute of Laser Technologies, 2013.

[7] J. Wilkes, Y. Hagedorn, W. Meiners, and K. Wissenbach, "Additive manufacturing of $\mathrm{ZrO}_{2}-\mathrm{Al}_{2} \mathrm{O}$ ${ }_{3}$ ceramic components by selective laser melting," Rapid Prototyp. J., vol. 19, no. 1, pp. 51-57, Jan. 2013.

[8] C. E. Protasov, R. S. Khmyrov, S. N. Grigoriev, and A. V. Gusarov, "Selective laser melting of fused silica: Interdependent heat transfer and powder consolidation," Int. J. Heat Mass Transf., vol. 104, pp. 665-674, Jan. 2017.

[9] W. Wang, Y. Liu, J. Y. H. Fuh, and P. Wang, "Alumina-zirconia-silica ceramics synthesis by selective laser sintering /melting," Appl. Mech. Mater., vol. 121-126, pp. 2487-2491, 2012. 
[10] S. Chang, L. Li, L. Lu, and J. Y. H. Fuh, "Selective laser sintering of porous silica enabled by carbon additive," Materials (Basel)., vol. 10, no. 11, 2017.

[11] A. Streek, P. Regenfuss, R. Ebert, and H. Exner, "Laser micro sintering - Upgrade of the technology," in International Congress on Applications of Lasers \& Electro-Optics, 2009, vol. 2009, no. 1, pp. 1140-1147.

[12] L. Moniz, C. Colin, J.-D. Bartout, K. Terki, and M.-H. Berger, "Laser Beam Melting of Alumina: Effect of Absorber Additions," JOM, vol. 70, no. 3, pp. 328-335, Mar. 2018.

[13] S. Pfeiffer et al., "Iron Oxide Doped Spray Dried Aluminum Oxide Granules for Selective Laser Sintering and Melting of Ceramic Parts," Adv. Eng. Mater., p. 1801351, Mar. 2019.

[14] K. Florio et al., "An Innovative Selective Laser Melting Process for Hematite-Doped Aluminum Oxide," Adv. Eng. Mater., p. 1801352, Mar. 2019.

[15] J. Lewis, D. Schwarzenbach, H. D. Flack, and IUCr, "Electric field gradients and charge density in corundum, $\alpha-\mathrm{Al}_{2} \mathrm{O}_{3}$," Acta Crystallogr. Sect. A, vol. 38, no. 5, pp. 733-739, Sep. 1982.

[16] E. Wolska and W. Szajda, "The effect of cationic and anionic substitution on the $\alpha$-(Al, Fe)2O3lattice parameters," Solid State lonics, vol. 28-30, no. PART 2, pp. 1320-1323, 1988.

[17] E. Wolska and U. Schwertmann, "Nonstoichiometric structures during dehydroxylation of goethite," Zeitschrift für Krist. - Cryst. Mater., vol. 189, no. 1-4, pp. 223-238, Jan. 1989.

[18] S. Popović, M. Ristić, and S. Musić, "Formation of solid solutions in the system Al2O3-Fe2O3," Mater. Lett., vol. 23, no. 1-3, pp. 139-142, Apr. 1995.

[19] I. W. M. Brown, K. J. D. Mackenzie, and C. M. Cardile, "Lattice parameters and Mössbauer spectra of iron-containing corundum ( $\alpha$-Al2O3)," J. Mater. Sci. Lett., vol. 6, no. 5, pp. 535-540, May 1987.

[20] L. M. ATLAS and W. K. SUMIDA, "Solidus, Subsolidus, and Subdissociation Phase Equilibria in the System Fe-Al-O," J. Am. Ceram. Soc., vol. 41, no. 5, pp. 150-160, May 1958.

[21] L. Dreval, T. Zienert, and O. Fabrichnaya, "Calculated phase diagrams and thermodynamic properties of the Al2O3-Fe2O3-FeO system," J. Alloys Compd., vol. 657, pp. 192-214, Feb. 2016.

[22] J. K. Bristow, D. Tiana, S. C. Parker, and A. Walsh, "Defect chemistry of Ti and Fe impurities and aggregates in Al203," J. Mater. Chem. A, vol. 2, no. 17, pp. 6198-6208, Apr. 2014.

[23] P. W. M. Jacobs and E. A. Kotomin, "Defect energies for pure corundum and for corundum doped with transition metal ions," Philos. Mag. A, vol. 68, no. 4, pp. 695-709, Oct. 1993.

[24] J. TARTAJ and G. L. MESSING, "Effect of the addition of $\alpha$-Fe2O3 on the microstructural development of boehmite-derived alumina," J. Mater. Sci. Lett., vol. 16, no. 2, pp. 168-170, 1997.

[25] J. Tartaj and G. L. Messing, “Anisotropic grain growth in $\alpha$-Fe2O3-doped alumina," J. Eur. Ceram. Soc., vol. 17, no. 5, pp. 719-725, Jan. 1997.

[26] J. L. McArdle and G. L. Messing, "Transformation, Microstructure Development, and Densification in alpha-Fe203-Seeded Boehmite-Derived Alumina," J. Am. Ceram. Soc., vol. 76, no. 1, pp. 214-222, Jan. 1993.

[27] P. Zhao, H. Zhao, J. Yu, H. Zhang, H. Gao, and Q. Chen, "Crystal structure and properties of Al2O3-Cr2O3 solid solutions with different $\mathrm{Cr} 2 \mathrm{O} 3$ contents," Ceram. Int., vol. 44, no. 2, pp. 1356-1361, Feb. 2018.

[28] X. Cheng et al., "Enhanced performance of chemical looping combustion of methane by combining oxygen carriers via optimizing the stacking sequences," Appl. Energy, vol. 230, pp. 696-711, Nov. 2018.

[29] N. S. Yüzbasi, A. Kierzkowska, and C. Müller, "Development of Fe2O3-based, Al2O3-stabilized Oxygen Carriers using Sol-gel Technique for H2 Production via Chemical Looping," Energy Procedia, vol. 114, pp. 436-445, Jul. 2017.

[30] Y. Çelik, E. Suvacı, A. Weibel, A. Peigney, and E. Flahaut, "Texture development in Fe-doped alumina ceramics via templated grain growth and their application to carbon nanotube growth," J. Eur. Ceram. Soc., vol. 33, no. 6, pp. 1093-1100, Jun. 2013.

[31] H. Jiao et al., "Nb2O5- $\gamma$-Al2O3 nanofibers as heterogeneous catalysts for efficient conversion of glucose to 5-hydroxymethylfurfural," Sci. Rep., vol. 6, no. 1, p. 34068, Dec. 2016.

[32] P. Tartaj and J. Tartaj, "Microstructural evolution of iron-oxide-doped alumina nanoparticles synthesized from microemulsions," Chem. Mater., vol. 14, no. 2, pp. 536-541, 2002.

[33] P. R. Willmott et al., "The Materials Science beamline upgrade at the Swiss Light Source," J. 
Synchrotron Radiat., vol. 20, no. 5, pp. 667-682, Sep. 2013.

[34] A. Bergamaschi et al., "The MYTHEN detector for X-ray powder diffraction experiments at the Swiss Light Source," J. Synchrotron Radiat., vol. 17, no. 5, pp. 653-668, Sep. 2010.

[35] “DIFFRAC.SUITE TOPAS - XRD Software, X-ray diffraction - XRD Software | Bruker." [Online]. Available: https://www.bruker.com/products/x-ray-diffraction-and-elemental-analysis/x-raydiffraction/xrd-software/topas.html. [Accessed: 04-Oct-2018].

[36] K. Wefers, Oxides and hydroxides of aluminum (1987 edition) / Open Library. Alcoa Research Laboratories, 1987.

[37] I. Levin and D. Brandon, "Metastable Alumina Polymorphs: Crystal Structures and Transition Sequences," J. Am. Ceram. Soc., vol. 81, no. 8, pp. 1995-2012, Jan. 2005.

[38] S. Lamouri et al., "Control of the $\psi$-alumina to $\alpha$-alumina phase transformation for an optimized alumina densification," Boletín la Soc. Española Cerámica y Vidr., vol. 56, no. 2, pp. 47-54, Mar. 2017.

[39] C. S. Nordahl and G. L. Messing, "Sintering of $\alpha$-Al2O3-seeded nanocrystalline $\gamma$-Al2O3powders," J. Eur. Ceram. Soc., vol. 22, no. 4, pp. 415-422, 2002.

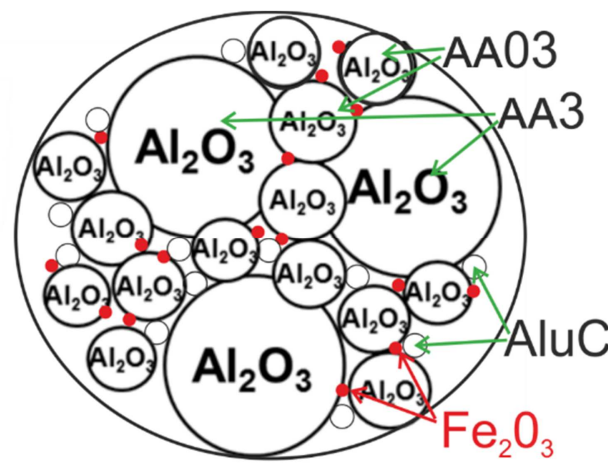

Figure 1 Scheme of a trimodal alumina granule prepared for SLM manufacturing. 
a)
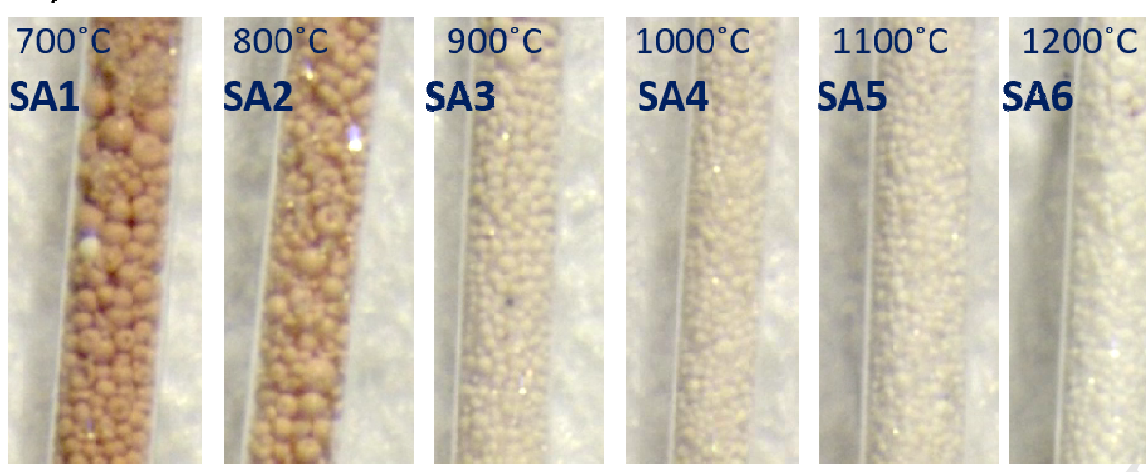

$1300^{\circ} \mathrm{C}$

SA3

SA4

SA5

SA7

b) SB1
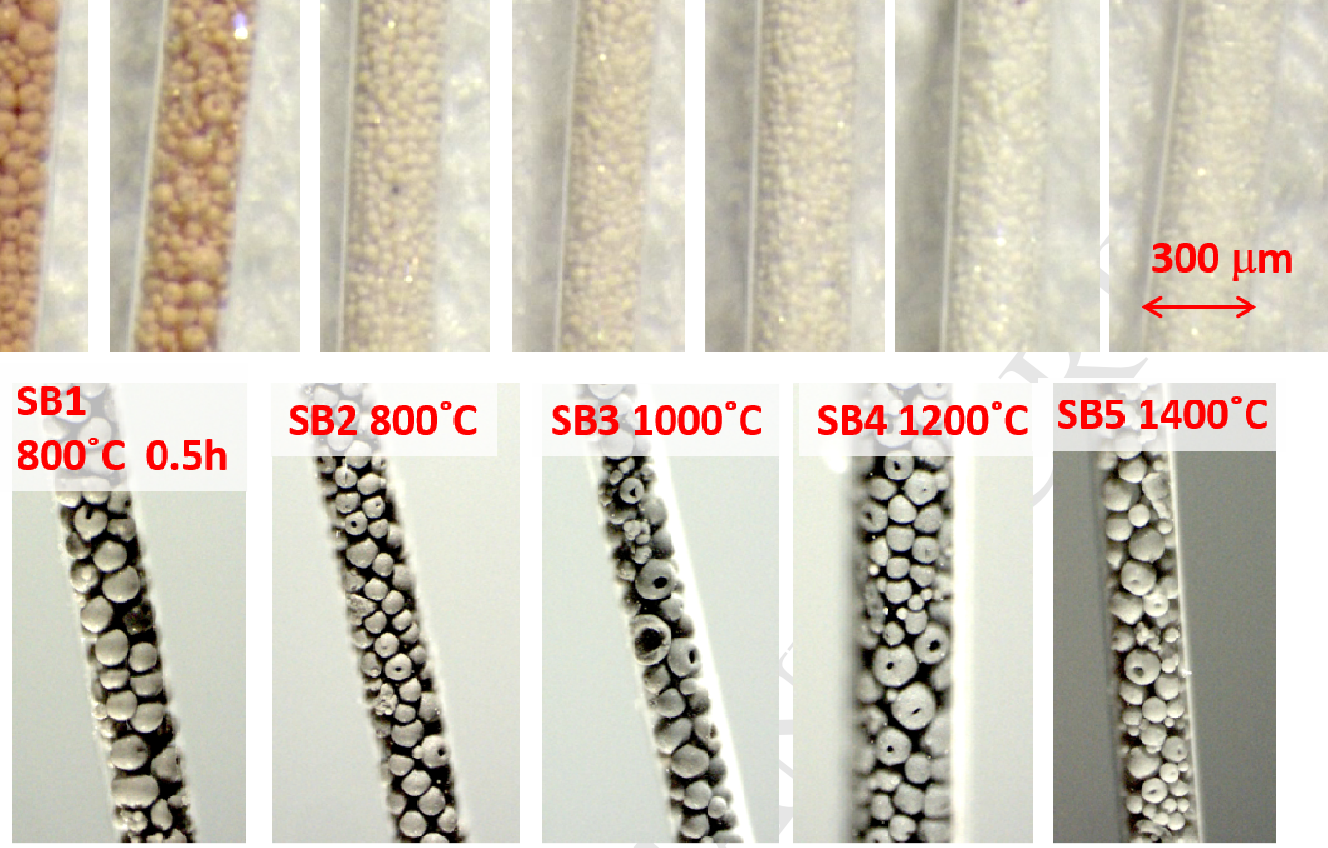

Figure 2 Optical microscopy images of capillaries containing trimodal alumina granules for SLM calcined at different temperatures (the same length scale for $a$ and $b$ ). 

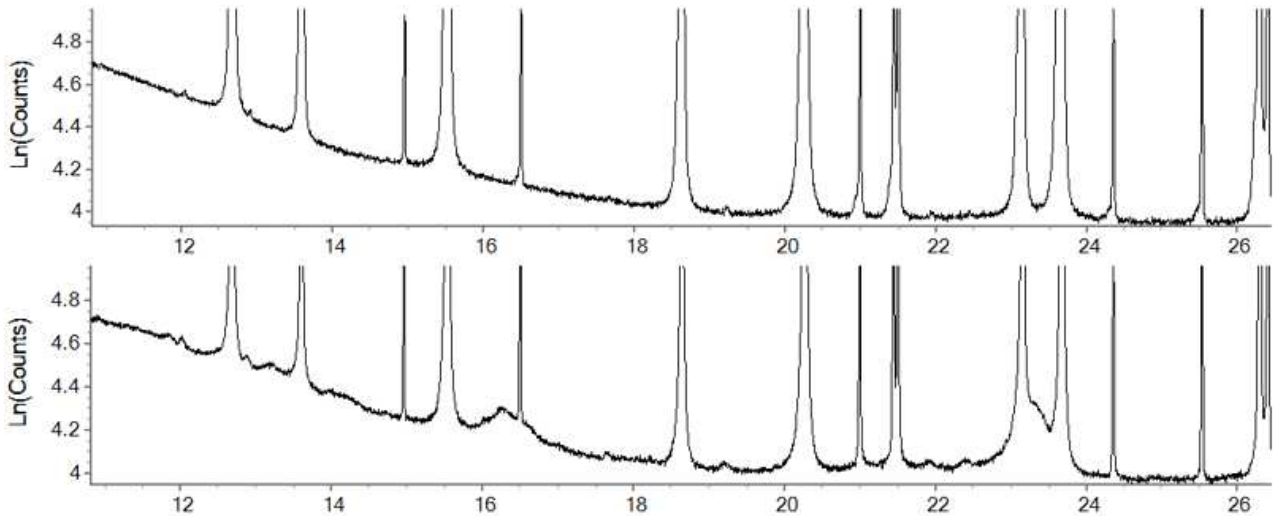

$1000^{\circ} \mathrm{C}$

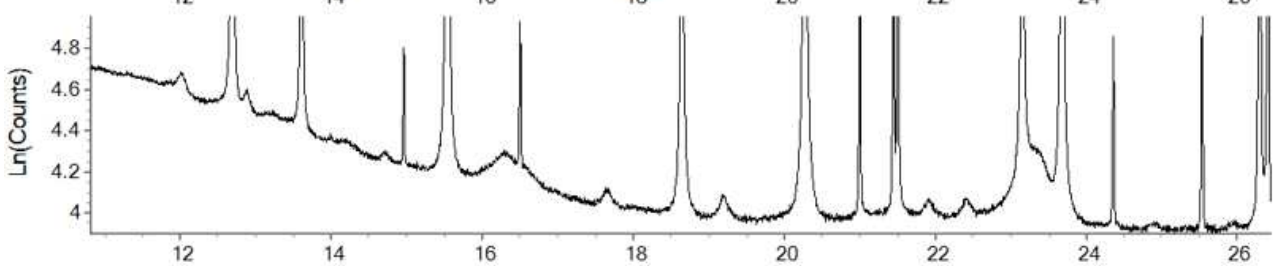

SA3

$800^{\circ} \mathrm{C}$

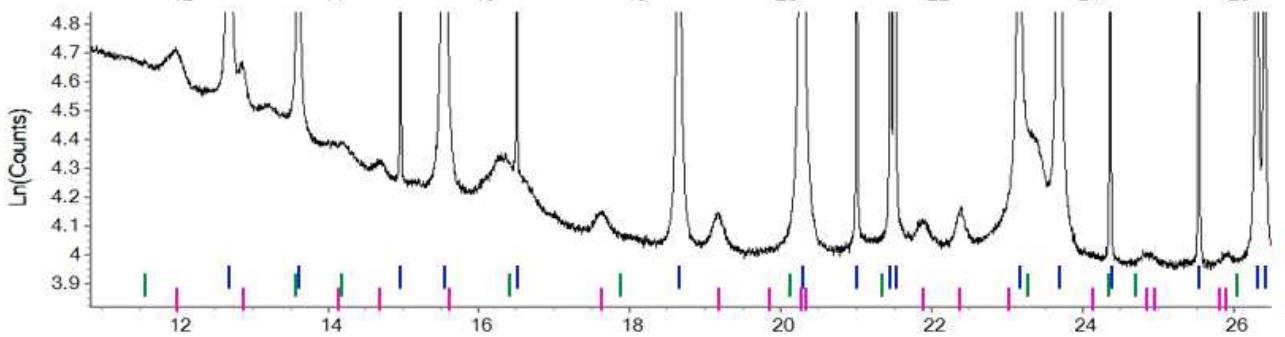

SA2

$700^{\circ} \mathrm{C}$

hematite $\alpha$-alumina Y-alumina

Figure 3 Comparison of powder diffraction patterns for air calcination temperatures $700{ }^{\circ} \mathrm{C}, 800{ }^{\circ} \mathrm{C}, 900{ }^{\circ} \mathrm{C}$ and $1000^{\circ} \mathrm{C}$.

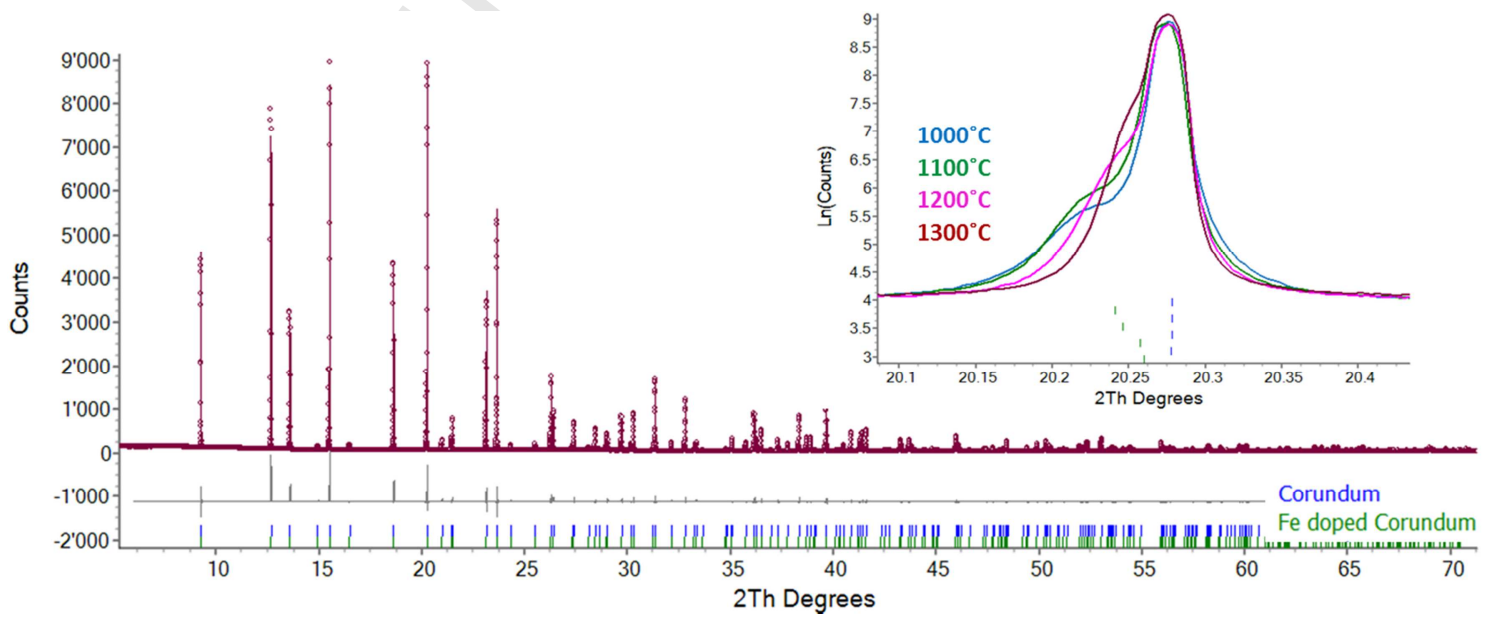

Figure 4 Powder diffraction pattern of calcined trimodal alumina granules doped with hematite (the parameters achieved for the Rietveld refinement were: $R w p=2.98 \%, R p=3.17 \%$ ). The inset shows a selected peak profile for powders calcined at different temperatures (not distinguishable in the main graph). 

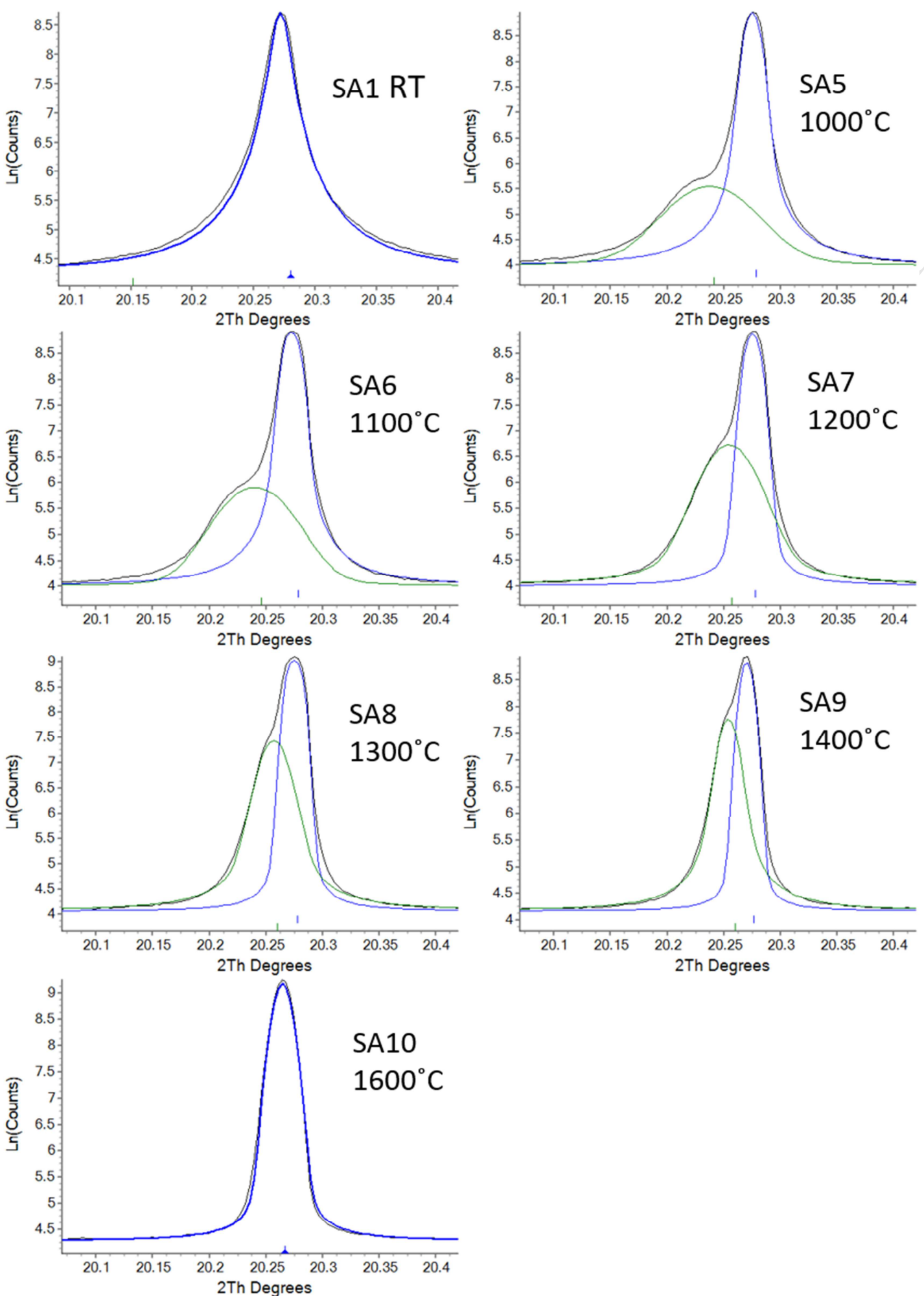

Figure 5 Comparison of initial powder and powders calcined at RT, $1000^{\circ} \mathrm{C}, 1100^{\circ} \mathrm{C}, 1200^{\circ} \mathrm{C}, 1300^{\circ} \mathrm{C}, 1400{ }^{\circ} \mathrm{C}$, $1600{ }^{\circ} \mathrm{C}$. Green and blue lines represent peaks fitted to the structure of Fe- doped alumina (refining different doping levels for different temperatures) and to the structure with minor amount of Fe. 

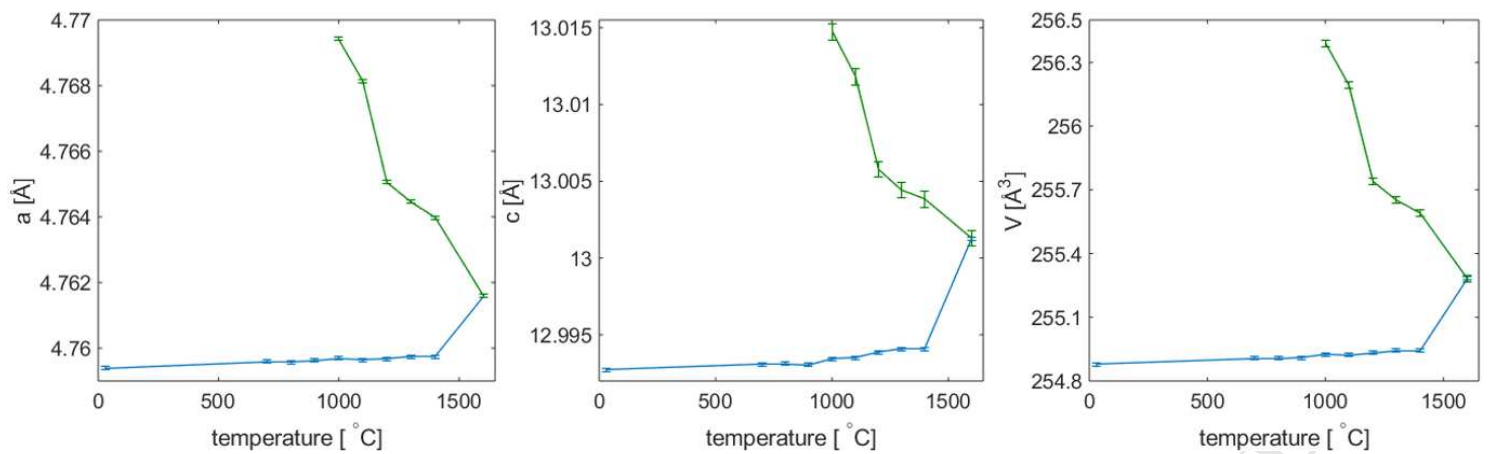

Figure 6 Lattice parameters $a$ and $c$ and unit cell volume evaluated for two phases (pure corundum- blue line, Fedoped corundum- green line) for samples SA1-SA10 derived from Rietveld refinement of the PD patterns. 

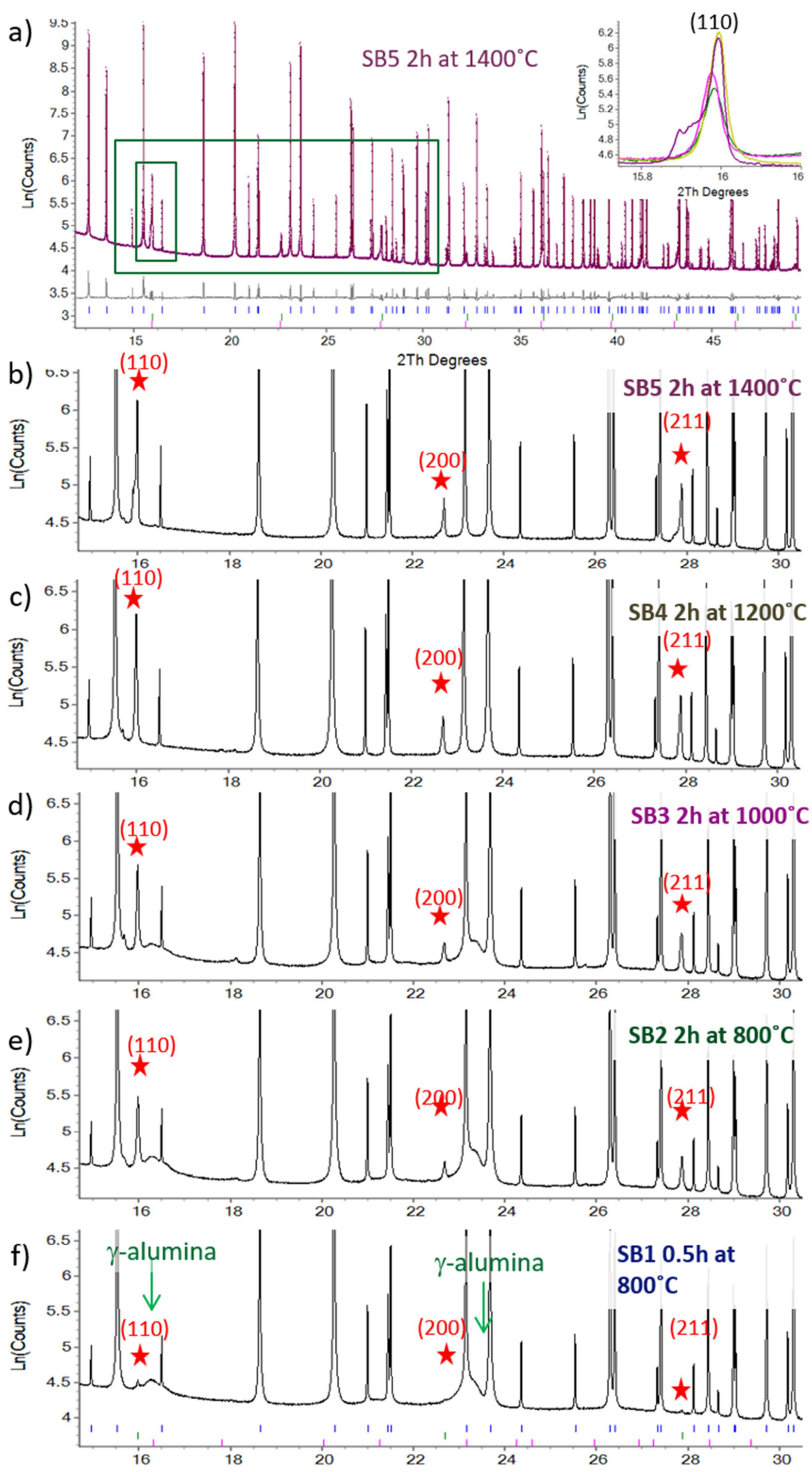

Figure 7 Powder diffraction of samples SB1-SB5. The rectangles marked in fig. a) represent the range presented in the inset showing (110) bcc iron peak profile for different temperatures (line colors correspond to the font color of text describing temperature in b)-f)) (small rectangle) and the range displayed in b)-f) (large rectangle). Red stars in b)-f) correspond to the bcc Fe structure reflections. The parameters achieved for the Rietveld refinement of the pattern in a) were: $w R p=3.06 \%, R p=3.86 \%$. 


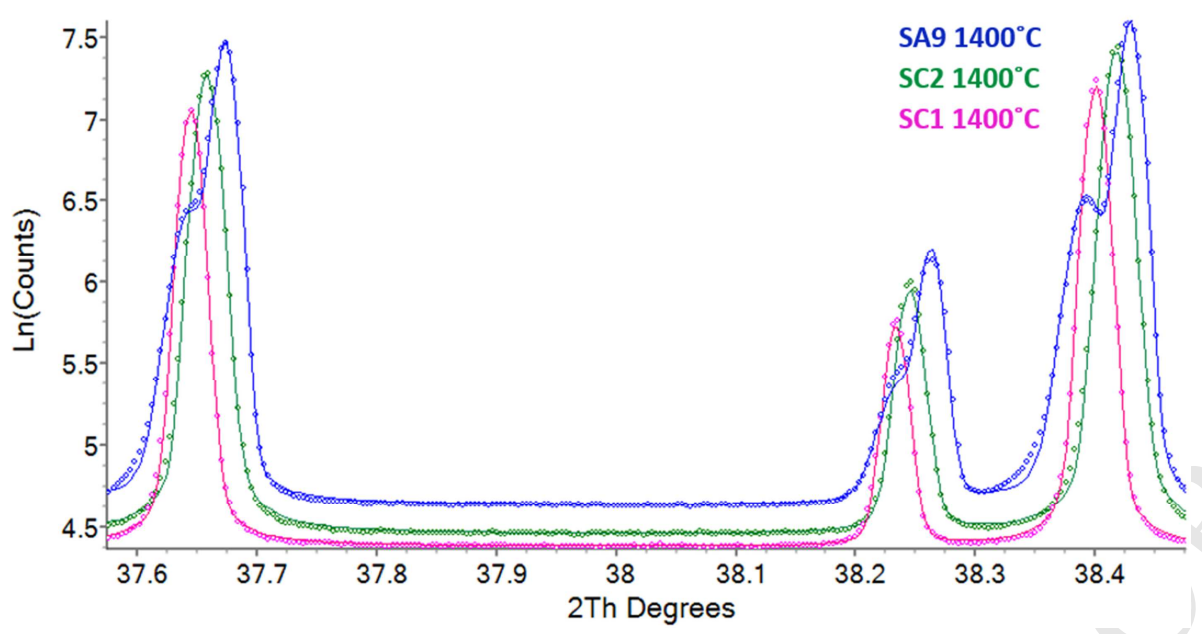

Figure 8 Diffraction patterns of monomodal alumina granules (samples SC1, SC2), compared with trimodal granules (SA9) calcined in air at $1400^{\circ} \mathrm{C}$ (markers- experimental data, solid lines - fitted model).

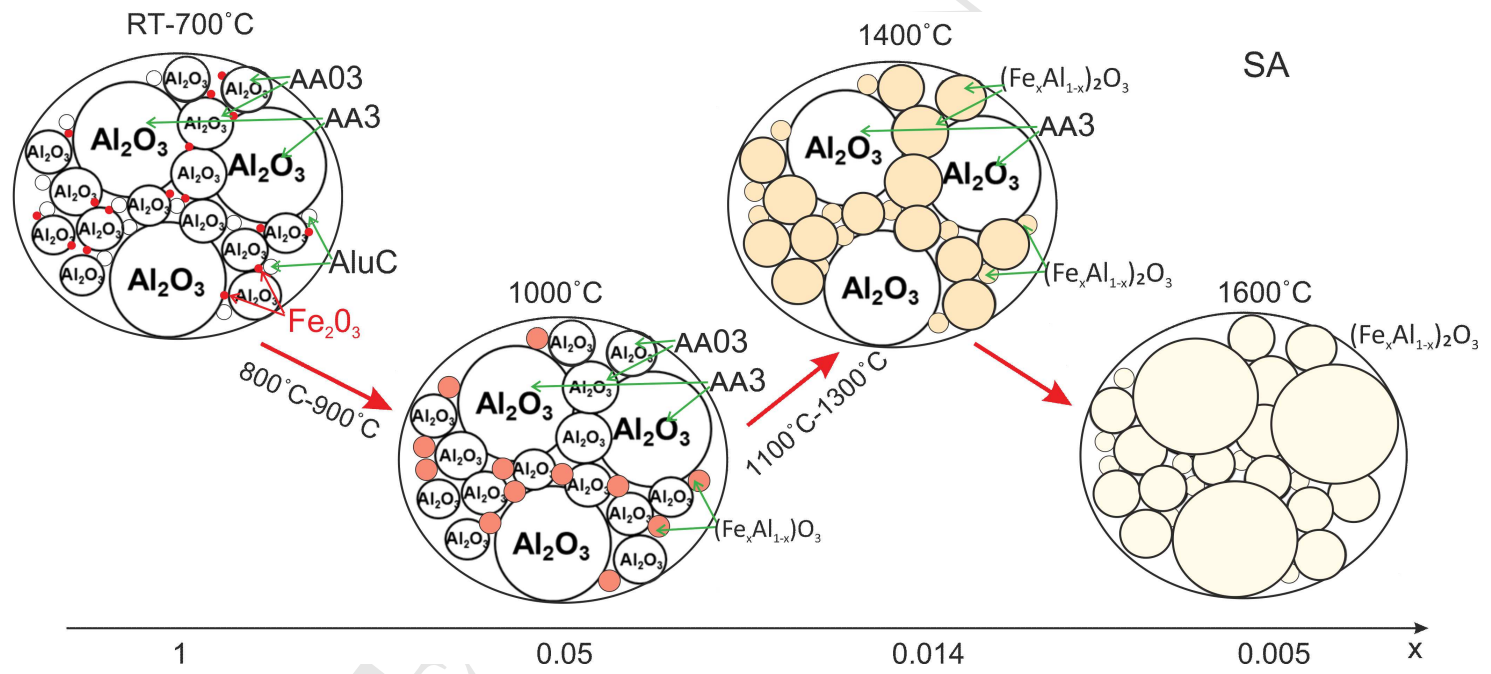

Figure 9 Sketch of the changes of the Fe distribution in the trimodal alumina granules during calcination at different temperatures ( $x$ axis corresponds to $\mathrm{Fe}$ doping level in $\left.\left(\mathrm{Fe}_{\mathrm{x}} \mathrm{Al}_{1-\mathrm{x}}\right)_{2} \mathrm{O}_{3}\right)$.

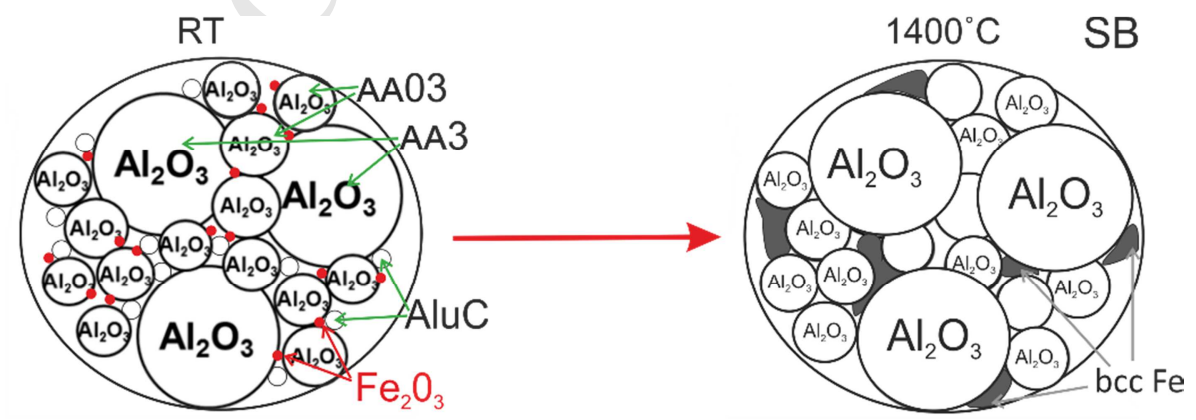

Figure 10 Sketch of the changes of the Fe distribution in the trimodal alumina granules during calcination in reducing atmosphere. 